\title{
A Continuous $\beta$-NiAl Layer Forming at the Interface of a MCrAlY and CMSX-4
}

Kang Yuan, Ru Peng and Xin-Hai Li

\section{Linköping University Post Print}

\section{Tweet}

N.B.: When citing this work, cite the original article.

The original publication is available at www.springerlink.com:

Kang Yuan, Ru Peng and Xin-Hai Li, A Continuous $\beta$-NiAl Layer Forming at the Interface of a MCrAlY and CMSX-4, 2016, Journal of thermal spray technology (Print), (25), 1, 244-251. http://dx.doi.org/10.1007/s11666-015-0293-4

Copyright: Springer Verlag (Germany)

http://www.springerlink.com/?MUD=MP

Postprint available at: Linköping University Electronic Press

http://urn.kb.se/resolve?urn=urn:nbn:se:liu:diva-123740 


\section{A Continuous $\beta$-NiAl Layer Forming at the Interface of a MCrAlY and CMSX-4}

Kang Yuan ${ }^{1}, \mathrm{Ru}$ Lin Peng ${ }^{1, *}$, Xin-Hai $\mathrm{Li}^{2}$

${ }^{1}$ Department of Management and Engineering, Linkoping University, SE-58183 Linkoping, Sweden

${ }^{2}$ Siemens Industrial Turbomachinery AB, SE-61283 Finspång, Sweden

*Corresponding author: E-mail: ru.peng@liu.se

Keywords: $\beta$-layer; CMSX-4; MCrAlY; diffusion; Al activity.

Abstract.

A large test sample of single crystal superalloy (CMSX-4) deposited with a MCrAlY coating of $\gamma$ and $\beta$ phases was subjected to a thermal-cycling fatigue (TCF) test at $1100{ }^{\circ} \mathrm{C}$ for about 300 cycles. Near the coating-substrate interface where an inner $\beta$-depletion zone often develops in the coating for other superalloy-MCrAlY systems, a continuous $\beta$-layer was formed instead for this particular system after the TCF test. The formation of the $\beta$-layer was related to the accumulation of $\mathrm{Al}$ at the interface. Simulations using an oxidation-diffusion model were carried out on this and a number of other superalloy-MCrAlY systems. It was derived that the formation of the $\beta$-layer at the interface was likely due to the high Al activity of CMSX-4 which resisted the inward diffusion of $\mathrm{Al}$ from the coating. The simulation results also indicated a positive effect provided by the formation of the $\beta$-layer on the coating's oxidation resistance.

1. Introduction 
MCrAlY ( $\mathrm{M}=\mathrm{Ni}$, Co) coatings are widely used as overlays or bond coats in thermal barrier coating (TBC) systems in aerospace engines and industrial gas turbines nowadays [1-3]. In an oxidation process at high temperature, a thermally-grown oxide (TGO), preferably alumina, forms at the MCrAlY coating surface and protects the underlying material from oxidation and corrosion. In a MCrAlY coating, the Al-rich $\beta$-NiAl phase, as Al reservoir, provides the coating surface with $\mathrm{Al}$ needed to maintain the protective TGO. Under continued thermal exposure, continued oxidation at the coating surface consumes $\mathrm{Al}$ in the coating and thus the $\beta$-phase. In addition, the coating also loses $\mathrm{Al}$ into the substrates due to the interdiffusion of alloying elements through coating-substrate interface (the substrate is considered to be an $\mathrm{Al}$ sink), leading to the development of an inner $\beta$-depletion zone of the coating near the interface $[4,5]$. If the diffusion of $\mathrm{Al}$ from the coating into the substrate can be hindered or slowed, more Al will be available for maintaining the protective TGO and therefore the coating life can be prolonged.

This paper is an extension of the ITSC2015 paper [6]. In the study, a continuous $\beta$-NiAl layer was observed to form automatically at the coating-substrate interface in a system of CMSX-4 substrate with a MCrAlY coating during a thermal cyclic test. Such a continuous $\beta$ layer may contribute to a better coating life as it can serve as an effective $\mathrm{Al}$ reservoir. The mechanism of the formation of the $\beta$-layer was analyzed based on experimental study and diffusion modeling.

\section{Experiments and model setting-up}

A large test sample of single crystal CMSX-4 was coated with a TBC system. The TBC was composed of a top coat (yttria-stabilized zirconia) and a MCrAlY bond coat. Both the top coat and the bond coat were deposited by electron-beam physical-vapor deposition (EB-PVD) 
technique. The compositions of the MCrAlY coating (c1) and the CMSX-4 substrate (s1) are presented in Table 1. Table 1 also gives the compositions of other coatings and substrates which were used for diffusion modeling in this paper.

The sample was tested in a thermal-cycling fatigue (TCF) rig. Each TCF cycle contained one-hour heating at $1100{ }^{\circ} \mathrm{C}$ in air and 10 -min forced-air cooling to about $100{ }^{\circ} \mathrm{C}$. The test was stopped after about 300 cycles. The cross section of the tested sample was finally investigated in a scanning electron microscope (SEM) equipped with an energy dispersive spectrometer (EDS) and an electron back-scattered diffraction (EBSD) detector.

A developed oxidation-diffusion model $[4,7,8]$ was adopted to study the influence of heating at $1100{ }^{\circ} \mathrm{C}$ on systems combining the substrates and coatings given in Table 1 . The modelling scheme is as follows (Fig. 1): 1) Al was removed from the outmost nodes to simulate the consumption of $\mathrm{Al}$ due to surface oxidation, 2) a homogenization diffusion simulation was done in the coating-substrate system using the DICTRA software from Thermo-Calc, 3) the previous two steps were cycled until the predetermined heating time was reached. The diffusivities of alloying elements at $1100{ }^{\circ} \mathrm{C}$ were calculated in DICTRA software using the Ni-based databases (TCNI6 and MOBNI2) from Thermo-Calc. The oxidation rate of the coatings used in the model was described by a parabolic law as shown in Eq. 1.

$$
h=h_{0}+\left(k_{p} * t\right)^{0.5}
$$

In Eq.1, $h$ is TGO thickness (unit: $\mu \mathrm{m}$ ), $t$ is time (unit: hour), $h_{0}$ is original TGO thickness which was simply set as zero for the modeling in this paper, $k_{p}$ is the oxidation constant which from fitting to experimental data was found to be $0.157 \mu \mathrm{m}^{2} / \mathrm{h}$. 


\section{Results}

\subsection{Experimental observations in s1-c1 sample}

Fig. 2 shows a cross section of the s1-c1 sample before the TCF test. A typical $\gamma / \beta$ microstructure formed in the MCrAlY coating, while a $\gamma / \gamma^{\prime}$ microstructure existed in the single crystal CMSX-4. The $\beta$-phase was Al-rich (17 wt.\%) and the $\gamma$-phase was Al-poor (4.6 wt.\%). Between the top coat and the MCrAlY bond coat, a TGO of alumina was found $(<0.5 \mu \mathrm{m})$. The TGO grew to about $7 \mu \mathrm{m}$ after around 300 TCF cycles.

The microstructure in the sample changed during the TCF process; the developed microstructure after about 300 cycles is shown in Fig. 3a. As can be seen, the inner $\beta$-depletion zone, which is commonly found in superalloy-MCrAlY systems exposed to high temperatures, was absent in the current system. Instead, a continuous $\beta$-layer formed at the coating-substrate interface.

The cross section of the $\beta$-layer sample can be divided into six characteristic zones, shown in Fig. 3a. Zone I was the OBDZ. Zone II had a typical $\gamma / \beta$ microstructure. Zone III contained the $\beta$-layer. Zone IV was the GPDZ, in which some secondary $\beta$-phase and (Ta,Ti)carbides also formed. In zone V, many (Re, W)-rich precipitates (identified as the $\mu$-phase by EBSD measurement) formed in a $\gamma / \gamma^{\prime}$ matrix of $\gamma^{\prime}$-rich. Zone VI was the unaffected substrate with $\gamma / \gamma^{\prime}$.

The chemical concentration profiles in Fig. 3b and c indicated that extensive diffusion had occurred, resulting in the complex microstructural changes observed on both sides of the coating-substrate interface. Co and Cr diffused from the coating to the substrate while Ni moved in the opposite direction (Fig. 3b). The Al profile is particularly presented in Fig. 4. As it was shown, some Al from the coating and from zone IV diffused into the substrate in zone V, while 
some others from the coating were trapped at the coating-substrate interface, forming zone III with up to $17 \%$ Al. Diffusion of elements like Ta, W, Re, Mo from the substrate into the coating also occurred (Fig. 3c).

Fig. 5 shows more details in the $\beta$-layer. Along the $\beta$-phase grain boundaries another phase was found (marked by arrows in Fig. 5). As it was poor in Al but rich in Cr (see the Xray maps in Fig. 6) and was also indexed by EBSD measurement as FCC structure, it was likely a $\gamma$ phase. The small and black particles in Fig. 5 were alumina and Ti-rich phase (probably TiN) according to the EDS result (Fig. 6). The presence of the small oxides and nitrides indicated an inward diffusion of oxygen and nitrogen from the atmosphere into the coating.

\subsection{Modeling in s1-c1 system}

In our previous studies $[4,7,8]$, the "rule of mixture" (the 5th homogenization module in the DICTRA software, shorten as Ho5) has been adopted to calculate the elemental diffusivities in the multi-phase material systems. The Ho5 module is an upper diffusion bound for which the diffusion of elements in the high-mobility phase has a dominant role. The upper diffusion bound tends to be more applicable in cases where low-mobility phase(s) has a low volume faction in the microstructure. One successful application of the Ho5 module can be found in [4]. The diffusivity of an element $\left(D^{e f f}\right)$ in the Ho5 module was derived as below:

$$
D^{e f f}=\sum f^{i} D^{i}
$$


where $i$ denotes a phase, $f^{i}$ is the faction of phase $i$, and $D^{i}$ is the diffusivity of the element in phase $i$.

The simulated Al profile using the upper diffusion bound - Ho5 module, presented as red-dash curve in Fig. 7, however, failed to predict the formation of an Al-rich layer (and so a $\beta$-layer) at the coating-substrate interface. By using a lower diffusion bound - Ho1 module (lower Hashin-Shtrikman bound [9]), the formation of $\beta$-layer was successfully predicted (the black-solid line in Fig. 7). The Ho1 module derives the elemental diffusivity ( $D^{\text {eff }}$ ), for instance in a two-phase material (phase $i$ and phase $j$ ), by using the following equation:

$$
D^{e f f}=D^{i}+\frac{f^{i}}{\frac{1}{D^{j}-D^{i}}+\frac{f^{j}}{3 D^{i}}}
$$

A lower diffusion bound like the lower Hashin-Shtrikman bound (Ho1) becomes applicable when the low-mobility phase(s) is above a certain volume fraction. Using such a diffusion module appears to be reasonable in the current case since the real microstructure showed that the low-mobility $\beta$-phase was volumetrically dominant around the interface of the s1-c1 system. The simulation results using the Ho1 module are presented in Fig. 8 and Fig. 9. The development of $\mathrm{Al}$ in the $s 1-c 1$ system (Fig. 8) indicated that the Al peak was built up due to the movement of $\mathrm{Al}$ from the coating to the interface, which eventually promoted the formation of the $\beta$-layer (see Fig. 9a). The predicted characteristic zones in Fig. 9a basically agree with the experimental observation except for the $\gamma$-zone between the $\beta$-layer and $\gamma / \beta$-zone, which was not observed in the real microstructure (Fig. 3a). The secondary $\beta$ phase ( $\beta$ formed 
in the substrate) was usually not predicted by the model [4,7], which could be due to the limitation of the diffusion database used.

\subsection{Simulation (extending)}

After it had been shown to successfully predict the formation of the $\beta$-layer, the oxidation-diffusion model was further applied to other systems based on the substrates and coatings listed in Table 1. Fig. 10 compares the simulation result of the $s 1-c 1$ system with that of the systems taking s2 (IN-792) as the substrate. Experimental studies [10] had shown that an inner $\beta$-depletion zone formed near the coating-substrate interface and there was no $\beta$-layer forming in samples of s2-c2 and s2-c3 systems. The simulation results (Fig. 10a) agreed with that of the experimental observations. Furthermore, the application of coating $c 1$ on substrate $s 2$, i.e. the $s 2-c 1$ system did not generate an interface $\beta$-layer either. These results implied a more important role of the substrates rather than the coatings.

As the formation of $\beta$-phase is mainly dependent on the Al concentration, the calculated Al profiles are compared in Fig. 10b, which clearly show different diffusion behavior between the s1-c1 system and the other three systems with $s 2$ as substrate. It could be derived that in systems with s2 Al from the coatings had diffused into the substrate forming a concentration gradient over a relatively large depth in the substrate. On the other hand, in s1-c1 Al moving from the coating towards the substrate was mostly trapped at the coating-substrate interface resulting in the strong $\mathrm{Al}$ peak. The $\mathrm{Al}$ activity curves in Fig. 10c show a higher $\mathrm{Al}$ activity with s1 than with s2, which likely resulted in their different diffusion behavior as the movement of elements was an activity-driving phenomenon. 
The predicted changes of $\mathrm{Al}$ concentration at coating's surface with oxidation time at $1100^{\circ} \mathrm{C}$ are plotted in Fig. $10 \mathrm{~d}$ for the above four coating-substrate systems. As can be seen the s1-c1 system with the $\beta$-layer retained a sufficient surface Al level to a much longer exposure time than those systems without a $\beta$-layer, indicating a positive effect of the $\beta$-layer on prolonging the coating's life for oxidation protection. The arrows in the figure mark a more rapid $\mathrm{Al}$ depletion rate after the complete depletion of $\beta$-phase in the coatings.

The substrate composition in s1-c1 was modified to investigate possible effects of $\mathrm{Al}$ (s3), W and $\mathrm{Re}(\mathrm{s} 4)$ and $\mathrm{Cr}(\mathrm{s5})$. Although $\mathrm{Al}$ accumulation also occurred at the coatingsubstrate interface (Fig. 11b), the amount was not sufficiently high to promote the formation of a $\beta$-layer (Fig. 11a). The Al activities in these substrate variants were found to be lower than s1, which seemed to indicate again that the substrate's Al activity is a main cause for the formation of the $\beta$-layer at the coating-substrate interface. It should be noted that substrate $s 4$ had the same $\mathrm{Al}$ concentration as $s 1$ but no $\beta$-layer was predicted for $s 4-c 1$. The substrate's Al concentration was therefore not the only driving force for the formation of the $\beta$-layer.

A low $\mathrm{Al}$ diffusivity in the substrate may also lead to the accumulation of $\mathrm{Al}$ at coatingsubstrate interface, since if the $\mathrm{Al}$ moving in from the coating can not be quickly homogenized into the substrate, they may be trapped near the coating-substrate interface. This is, however, not the case for the s1-c1 system. The DICTRA calculation (Fig. 12) shows that the Al diffusivity in $s 1$ was not lower than the other substrates (s2, s3, s4, s5).

Examination of the simulation results on a large number of coating-substrate systems based on compositions in Table 1 generated a map for $\beta$-layer formation (Fig. 13). The result clearly showed that the $\mathrm{Al}$ activity of both the substrates and coatings affecting the formation of $\beta$-layer. The Al-activities of substrates depends on the chemical compositions. As shown in 
Table 2, it increased with increasing concentration of alloying elements like Al, Mo, Re, Cr, Ti, etc (balanced by $\mathrm{Ni}$ ).

\section{Discussion}

Whether or not a continuous $\beta$-layer can form in a coating-substrate system is largely dependent on the behavior of the diffusion of elements especially the $\mathrm{Al}$ in the system. Both the experimental work and simulations showed that $\beta$-depletion of the coating near the coatingsubstrate interface which was observed in s2-c2 and s2-c3 was inhibited in the s1-c1 sample. In another word, the inward diffusion of Al from the MCrAlY coating into the CMSX-4 substrate was slower than into the IN792 substrate. A substrate resisting inward diffusion of Al seemed to be essential for the formation of the $\beta$-layer at the interface. Indeed the simulations predicted a $\beta$-layer when c1, $c 2$ or c3 was combined with a CMSX-4 substrate but no $\beta$-layer when any of these coatings was applied on an IN792 substrate (Fig. 13). On the other hand, Fig. 13 also revealed the importance of the coating composition. No $\beta$-layer was expected when coatings $c 4$ and $c 5$ were combined with a CMSX-4 substrate. $c 4$ and $c 5$ has a lower $\mathrm{Al}$ concentration and thus lower $\mathrm{Al}$ activity than $c 1, c 2$ and $c 3$.

Fig. 10d revealed that the formation of $\beta$-layer may prolong the coating's oxidation life by providing the coating surface with the $\mathrm{Al}$ needed to maintain a protective scale to a longer thermal exposure time. The Al in the $\beta$-layer may be used only for forming Al oxide at coating surface or also could diffuse into the substrate after a long thermal exposure time. Further work with experiments and simulations are needed in the future to investigate the long term interdiffusion and oxidation behavior of the s1-c1 system. Fig. 13 and Table 2 suggested that 
increasing the substrate's $\mathrm{Al}$ activity can increase the possibility of $\beta$-layer formation. While increasing the $\mathrm{Al}$ concentration in the substrate seemed to be an efficient way to enhance the Al activity, the substrate's Al activity can also be enhanced via increasing the concentration of

elements of $\mathrm{Cr}$, Ta, Mo and Re (Ni as the balanced element). This indicated that selecting or tailoring the chemical composition to reduce the substrate's sinking effect on Al could be an effective way to enhance the oxidation resistance of the coated system.

\section{Conclusion}

A continuous $\beta$-NiAl layer was found near the coating-substrate interface in a sample of CMSX-4 deposited with MCrAlY subjected to a thermal cycling testing $\left(1100^{\circ} \mathrm{C}\right.$, for about 300 hours). The experimental study and simulations using an oxidation-diffusion model showed that the formation of the $\beta$-layer in this coating-substrate system was likely due to the high $\mathrm{Al}$ activity of the CMSX-4 substrate. The high Al activity is believed to reduce the substrate's sinking effect on $\mathrm{Al}$ such that $\mathrm{Al}$ moving from a coating with a sufficient concentration of $\mathrm{Al}$ towards the substrate is accumulated at the coating-substrate interface to form the $\beta$-layer. The simulation results also showed a positive effect provided by the $\beta$-layer on the coating's oxidation resistance.

The results of the current work indicate the potential and possibility of enhancing oxidation resistance of MCrAlY-superalloy systems by modifying superalloys composition to sufficiently inhibit the sinking effect of the substrate on Al. 
Acknowledgement

The Siemens Industrial Turbomachinery AB (Finspång, Sweden) is greatly acknowledged for its financial support in this research. The authors are also grateful for KME and Energiforsk in Sweden for their support and the Swedish Energy Agency for funding the project.

\section{References}

[1] N.P. Padture, M. Gell, E.H. Jordan, Thermal Barrier Coatings for Gas-Turbine Engine Applications, Science, 2002, 296(5566), p 280-284

[2] D.J. Wortman, B.A. Nagaraj, E.C. Duderstadt, Thermal Barrier Coatings for Gas Turbine Use, Mater. Sci. Eng. A, 1989, 120-121, Part 2(0), p 433-440

[3] S. Bose and J. DeMasi-Marcin, Thermal Barrier Coating Experience in Gas Turbine Engines at Pratt \& Whitney, J. Therm. Spray Technol., 1997, 6(1), p 99-104

[4] K. Yuan, R. Eriksson, R. Lin Peng, X. Li, S. Johansson, Y. Wang, Modeling of Microstructural Evolution and Lifetime Prediction of MCrAlY Coatings on Nickel Based Superalloys during High Temperature Oxidation, Surf. Coat. Technol., 2013, 232(0), p 204215

[5] T. Gomez-Acebo, B. Navarcorena, F. Castro, Interdiffusion in Multiphase, Al-Co-Cr-Ni-Ti Diffusion Couples, J. Phase Equilib. Diffu., 2004, 25(3), p 237-251

[6] K. Yuan, R. Lin Peng, X. Li, A Continuous $\beta$-NiAl Layer Forming at the Interface of a MCrAlY and CMSX-4, ITSC 2015-Proceedings of the International Thermal Spray Conference, 2015, p 54-61

[7] K. Yuan, R. Eriksson, R. Lin Peng, X. Li, S. Johansson, Y. Wang, MCrAlY Coating Design Based on Oxidation-Diffusion Modelling. Part I: Microstructural Evolution, Surf. Coat. Technol., 2014, 254(0), p 79-96

[8] R. Eriksson, K. Yuan, X. Li, R. Lin Peng, MCrAlY Coating Design Based on Oxidationdiffusion Modelling. Part II: Lifing Aspects, Surf. Coat. Technol., 2014, 253(0), p 27-37

[9] Z. Hashin and S. Shtrikman, A Variational Approach to the Theory of the Effective Magnetic Permeability of Multiphase Materials, J. Appl. Phys., 1962, 33(10), p 3125-3131 
[10] K. Yuan, R. Lin Peng, X. Li, S. Johansson, Y. Wang, Some Aspects of Elemental Behaviour in HVOF MCrAlY Coatings in High-Temperature Oxidation, Surf. Coat. Technol., 2015, 261(0), p 86-101 
Figure captions:

Figure 1: Oxidation-diffusion model.

Figure 2: Cross section of c1-s1 sample in as-received status.

Figure 3. Cross section of c1-s1 sample after the TCF test: (a) microstructures, (b) and (c) concentration profiles of elements across the cross section in figure (a).

Figure 4. Al concentration profile from Fig. 3b.

Figure 5. Microstructure details in the area with $\beta$ layer.

Figure 6. EDS maps of some elements in the area marked by square in Fig. 5.

Figure 7. Simulated Al profile using oxidation-diffusion model (1100 ${ }^{\circ} \mathrm{C}$ and 300 hours). The simulations used two homogenization modules: Ho1 (the general lower Hashin-Shtrikman bound) and Ho5 (the rule of mixture).

Figure 8. Simulation results showing the building-up of $\mathrm{Al}$ peak at the coating-substrate interface using Ho1 module.

Figure 9. Simulated composition profiles and microstructure using Ho1 module. The widths of the phase zones are marked by horizontal black bars in figure a.

Figure 10. Simulated profiles of (a) $\beta$ phase, (b) Al concentration and (c) Al activity in different substrate-coating systems by using Ho1 module. Figure (d) gives the development of Al content at the outmost coating area (the arrows mark the time when $\beta$ phase was depleted from the entire coating).

Figure 11. Simulated profiles of (a) $\beta$ phase, (b) Al concentration and (c) Al activity in substratecoating systems using Ho1 module with different substrates. 
Figure 12. Al diffusivity in different substrates at $1100{ }^{\circ} \mathrm{C}$ calculated by DICTRA using Ho1 and Ho5 modules.

Figure 13. The activity-activity map of $\mathrm{Al}$ showing the region for the formation of a continuous $\beta$ layer at coating-substrate interface based on simulations in different substratecoating systems. 
Table 1: Compositions of MCrAlY coatings and substrates (wt.\%).

\begin{tabular}{|c|c|c|c|c|c|c|c|c|c|c|c|}
\hline Material & $\mathrm{Ni}$ & Co & $\mathrm{Cr}$ & $\mathrm{Al}$ & $\mathrm{Y}$ & Si & $\mathrm{Ta}$ & $\mathrm{Ti}$ & Mo & $\mathrm{W}$ & $\operatorname{Re}$ \\
\hline$c 1$ (exp. coat.) & 50.3 & 22.2 & 14.7 & 11.4 & 0.1 & 0.3 & 1 & - & - & - & - \\
\hline$c 2$ (exp. coat.) & 46.1 & 25.6 & 15.7 & 11.2 & 0.8 & 0.3 & 0.5 & - & - & - & - \\
\hline c3 (exp. coat.) & 32.9 & 33.8 & 21.8 & 10.3 & 0.7 & 0.5 & - & - & - & - & - \\
\hline$c 4$ & 54.2 & 22.2 & 14.7 & 7.5 & 0.1 & 0.3 & 1 & - & - & - & - \\
\hline c5 & 64.1 & 15 & 12 & 7.5 & 0.1 & 0.3 & 1 & - & - & - & - \\
\hline s1 (CMSX-4) & 59.3 & 9.6 & 6.3 & 5.5 & - & - & 7 & 1 & 0.6 & 6.6 & 4 \\
\hline s2 (Inconel 792) & 59.8 & 9 & 12.4 & 3.3 & - & - & 4.7 & 3.9 & 2.1 & 4.8 & - \\
\hline s3 & 61.6 & 9.6 & 6.3 & 3.3 & - & - & 7 & 1 & 0.6 & 6.6 & 4 \\
\hline s4 & 67 & 9.6 & 6.3 & 5.5 & - & - & 7 & 1 & 0.6 & 3 & 0 \\
\hline s5 & 66.3 & 6 & 3 & 5.5 & - & - & 7 & 1 & 0.6 & 6.6 & 4 \\
\hline s6 & 56 & 9.6 & 6.3 & 5.5 & - & - & 7 & 1 & 2 & 6.6 & 6 \\
\hline s7 & 53.7 & 9.6 & 8 & 5.5 & - & - & 7 & 3 & 0.6 & 6.6 & 4 \\
\hline s8 & 60.2 & 9.6 & 6.3 & 3.3 & - & - & 7 & 1 & 2 & 6.6 & 6 \\
\hline s9 & 57.6 & 9 & 12.4 & 5.5 & - & - & 4.7 & 3.9 & 2.1 & 4.8 & - \\
\hline s10 & 54.5 & 12 & 12.4 & 3.3 & - & - & 7 & 3.9 & 2.1 & 4.8 & - \\
\hline s11 & 57.9 & 12 & 9 & 3.3 & - & - & 7 & 3.9 & 2.1 & 4.8 & - \\
\hline
\end{tabular}

Note: compositions of $c 1, c 2$ and $c 3$, and, $s 1$ and $s 2$, were measured by energy-dispersive spectroscopy (EDS). Other coating/substrate compositions were designed for simulation. 
Table 2: A summary of the substrates with which a $\beta$ layer can form (yes) or not form (no) at the coating-substrate interface based on the modeling results in Fig. 13. The concentration is in wt.\%.

\begin{tabular}{|c|c|c|c|c|c|c|c|c|c|c|c|c|c|}
\hline \multirow{3}{*}{$\begin{array}{l}\text { Material } \\
\text { s1 (ref.) }\end{array}$} & \multirow{3}{*}{$\begin{array}{l}\mathrm{Ni} \\
\text { bal. }\end{array}$} & \multirow{3}{*}{$\begin{array}{l}\text { Co } \\
9.6\end{array}$} & \multirow{3}{*}{$\begin{array}{l}\text { Cr } \\
6.3\end{array}$} & \multirow{3}{*}{$\begin{array}{l}\mathrm{Al} \\
5.5\end{array}$} & \multirow{3}{*}{$\begin{array}{l}\text { Y } \\
-\end{array}$} & \multirow{3}{*}{$\begin{array}{l}\mathrm{Si} \\
-\end{array}$} & \multirow{3}{*}{$\begin{array}{l}\text { Ta } \\
7.0\end{array}$} & \multirow{3}{*}{$\begin{array}{l}\mathrm{Ti} \\
\\
1.0\end{array}$} & \multirow{3}{*}{$\begin{array}{l}\text { Mo } \\
0.6\end{array}$} & \multirow{3}{*}{$\begin{array}{l}\text { W } \\
6.6\end{array}$} & \multirow{3}{*}{$\begin{array}{l}\text { Re } \\
4.0\end{array}$} & \multirow{2}{*}{\multicolumn{2}{|c|}{$\begin{array}{r}\text { yes or no forming } \beta \\
\text { layer }\end{array}$}} \\
\hline & & & & & & & & & & & & & \\
\hline & & & & & & & & & & & & yes* & \\
\hline s3 & bal. & & & 3.3 & & & & & & & & & no \\
\hline s4 & bal. & & & & & & & & & 3.0 & 0 & & no \\
\hline s5 & bal. & 6 & 3 & & & & & & & & & & no \\
\hline$s 6$ & bal. & & & & & & & & 2 & & 6 & yes & \\
\hline s7 & bal. & & 8 & & & & & 3 & & & & yes & \\
\hline s8 & bal. & & & 3.3 & & & & & 2 & & 6 & & no \\
\hline s2 (ref.) & bal. & 9.0 & 12.4 & 3.3 & - & - & 4.7 & 3.9 & 2.1 & 4.8 & - & & no \\
\hline s9 & bal. & & & 5.5 & & & & & & & & yes & \\
\hline s10 & bal. & 12 & & & & & 7 & & & & & & no \\
\hline s11 & bal. & 12 & 9 & & & & 7 & & & & & & no \\
\hline
\end{tabular}

* with substrate $s 1, \beta$ layer formed in $c 1, c 2$ and $c 3$ while did not form in $c 4$ and $c 5$. 


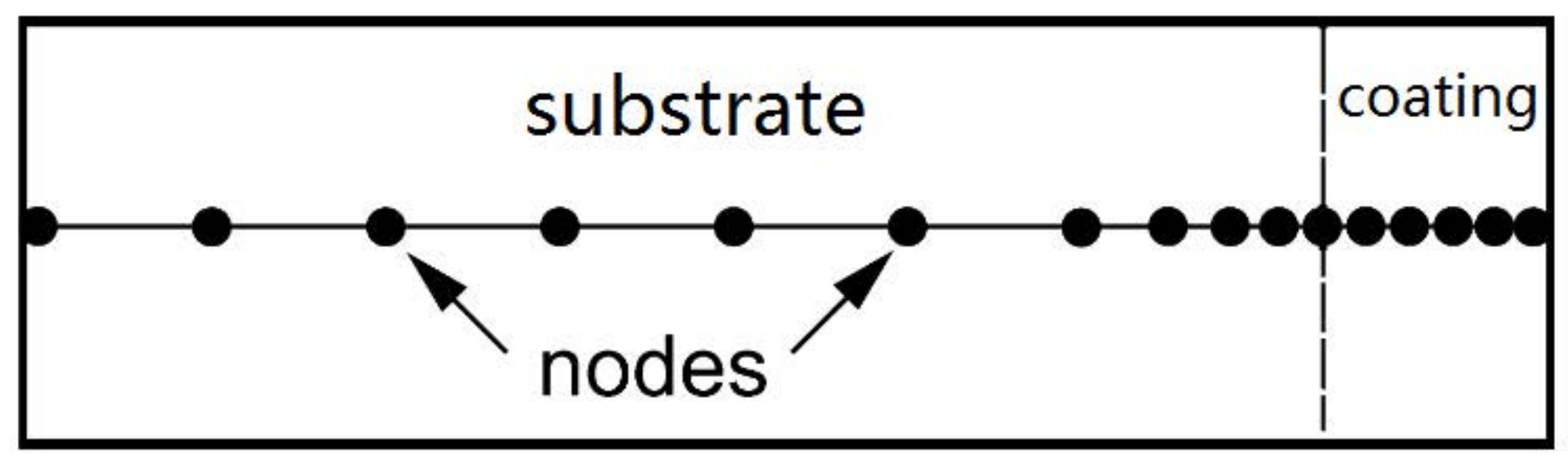

diffusion in substrate- coating system, $d t$ surface oxidation on coating, $d t$ $\bullet-\bullet \cdot 0 \cdot 0 \cdot 0000$

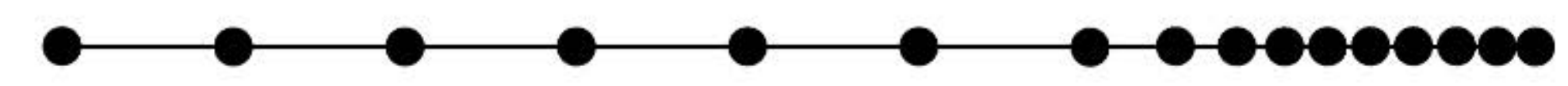


$-\mathrm{VI} \rightarrow \longleftarrow \mathrm{V} \longrightarrow \leftarrow \mathrm{IV} \longrightarrow \leftarrow \mathrm{III} \rightarrow \leftarrow \mathrm{II} \rightarrow \leftarrow \mathrm{I}-$ 


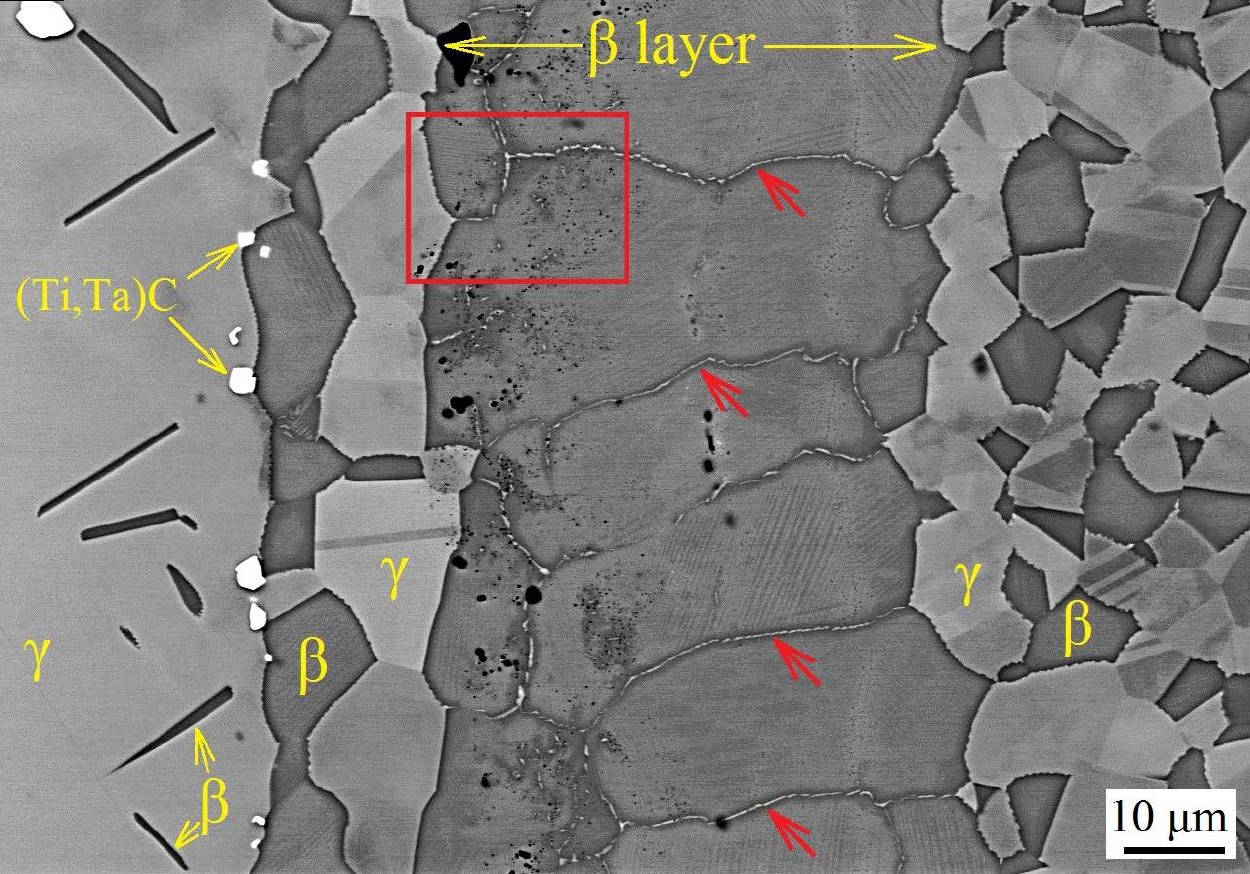


BSE 


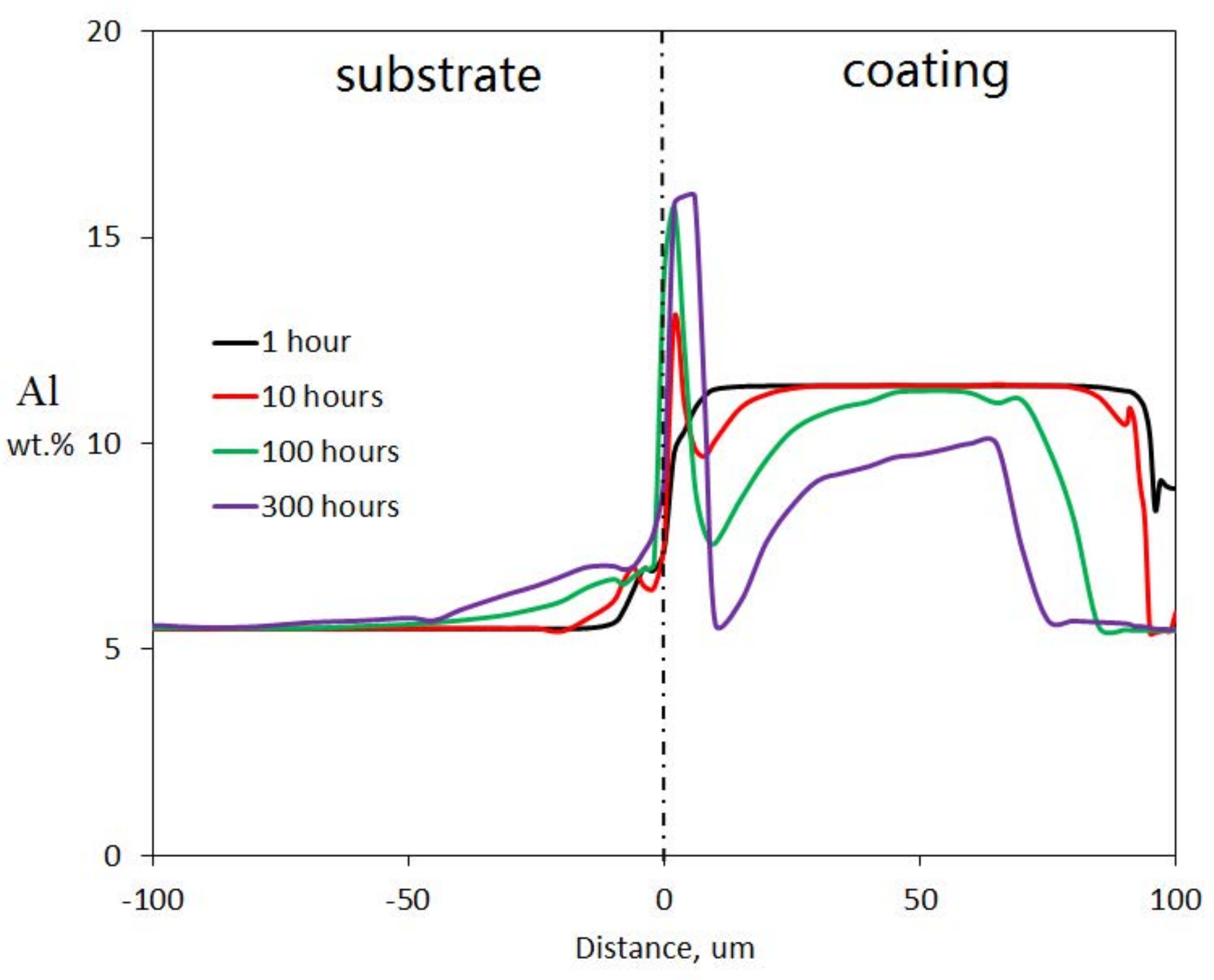



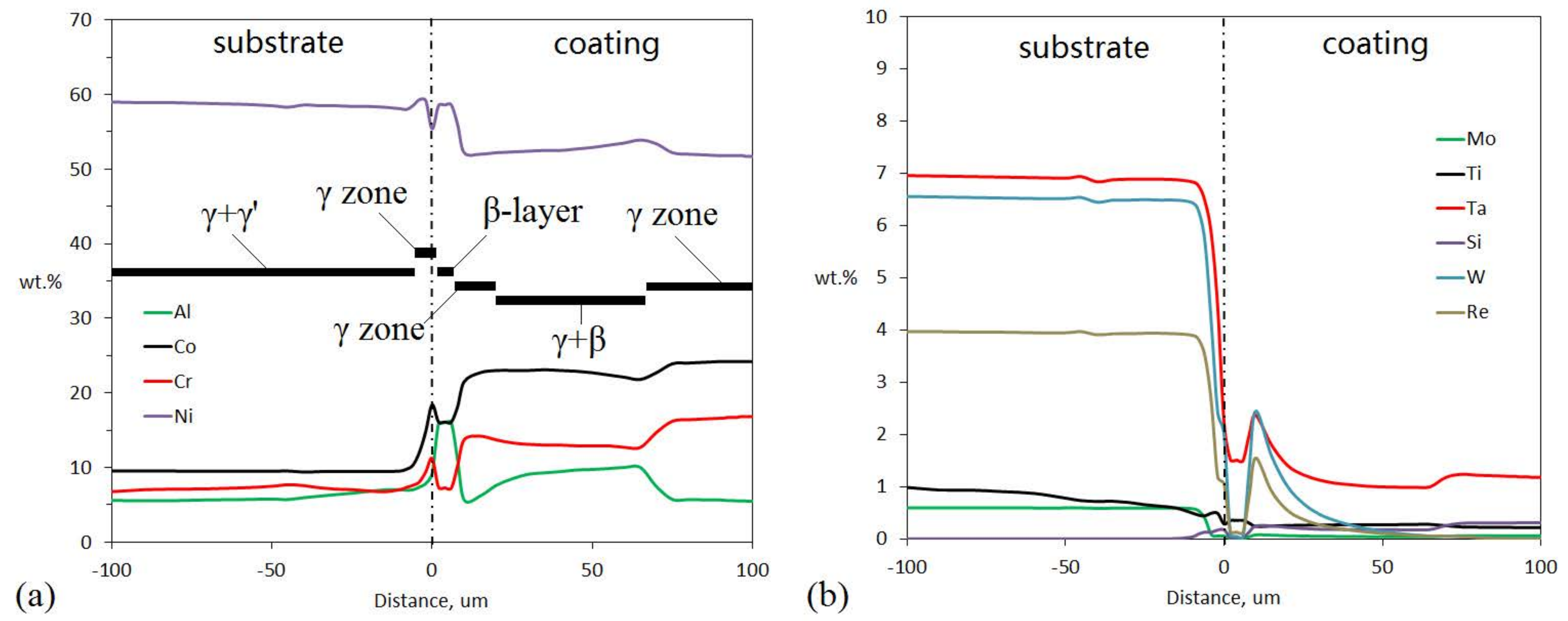

(b) 

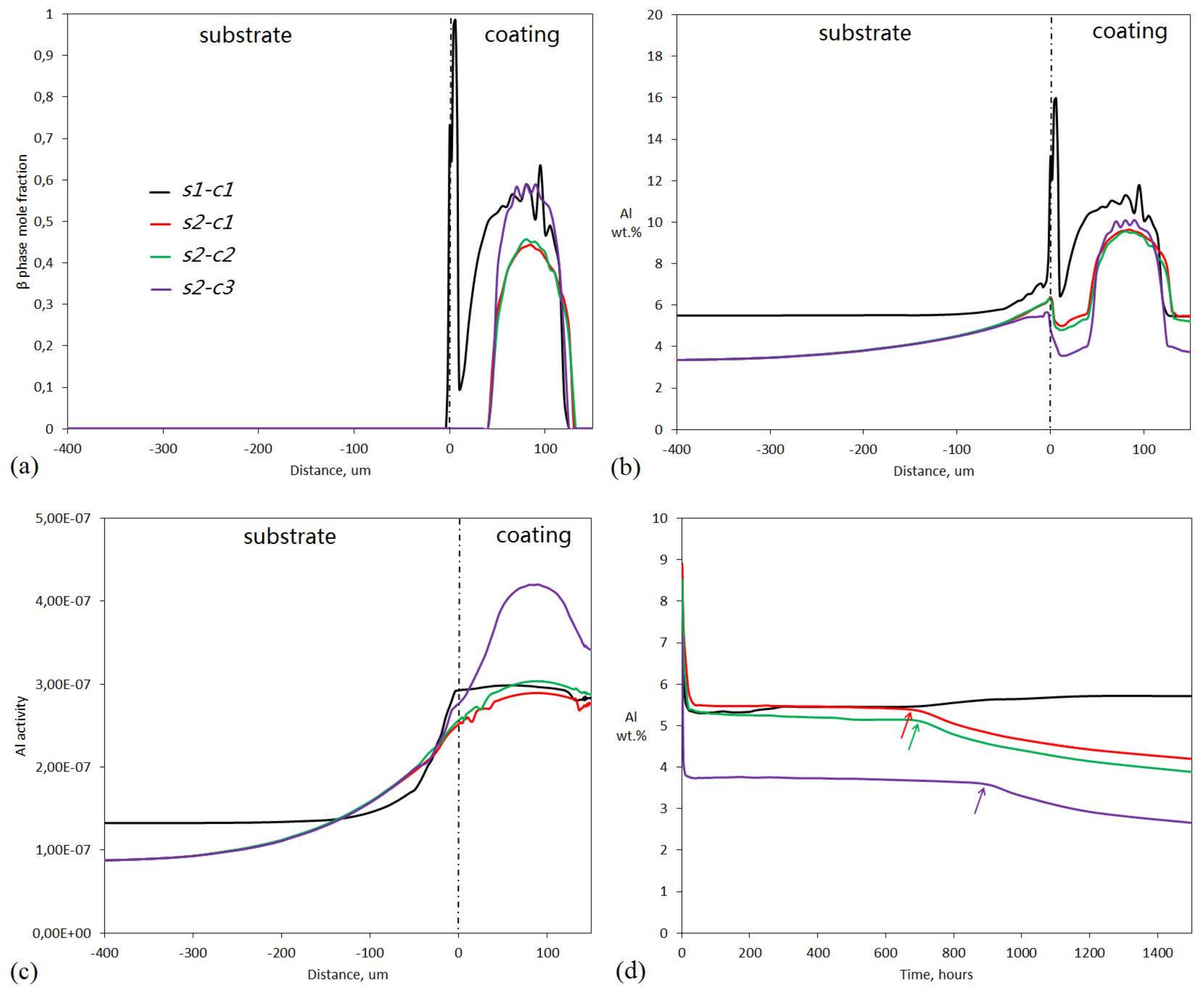

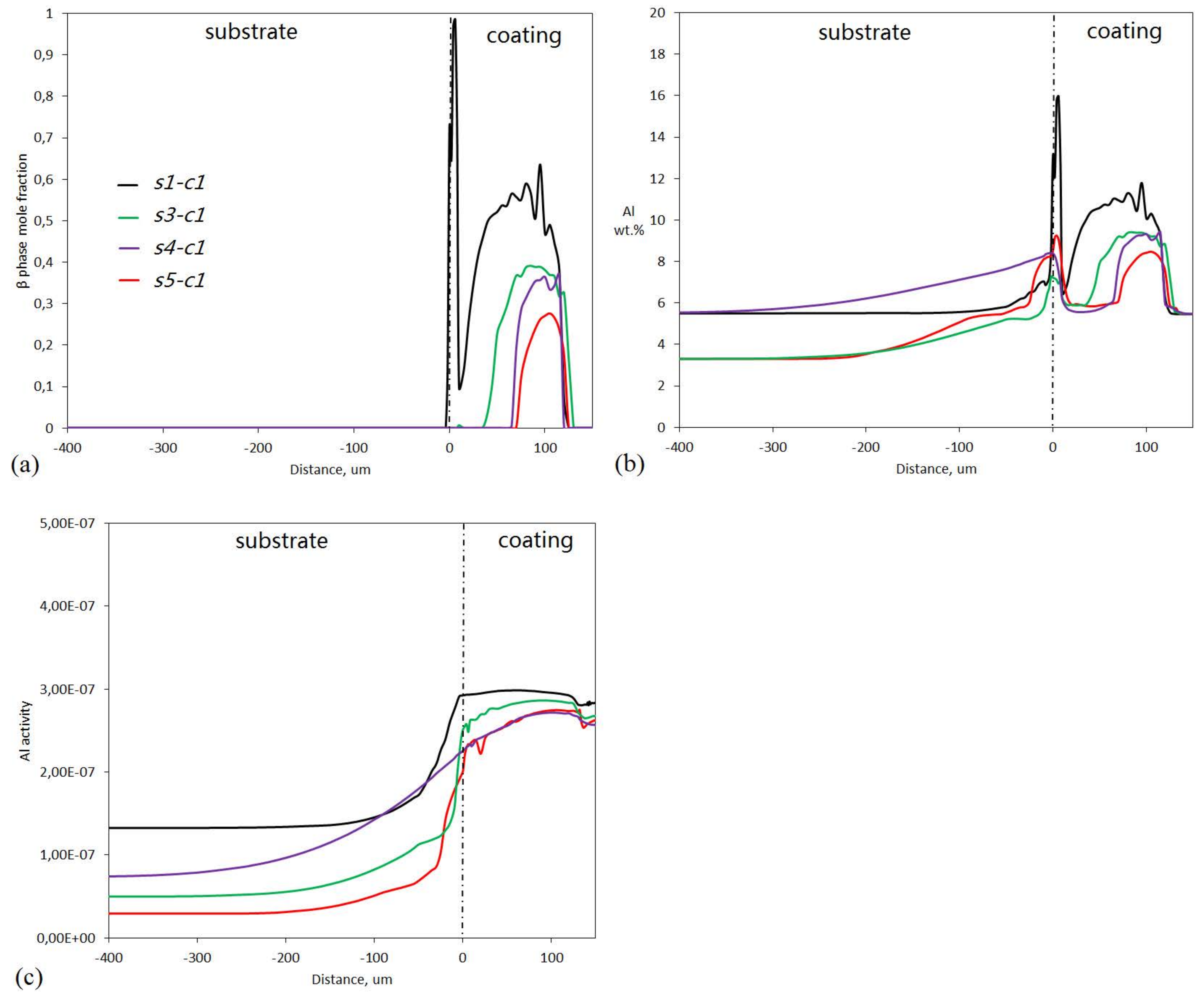


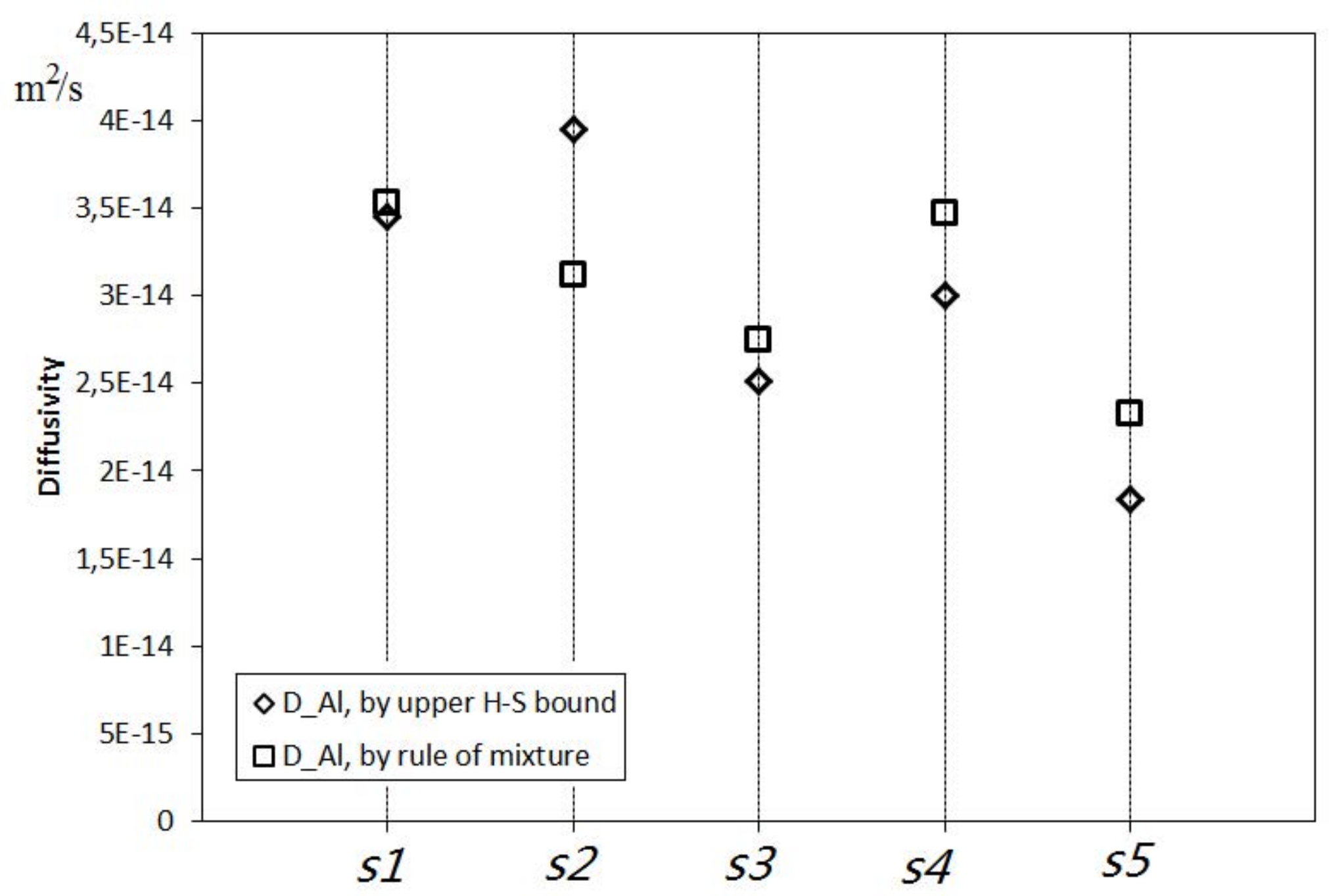




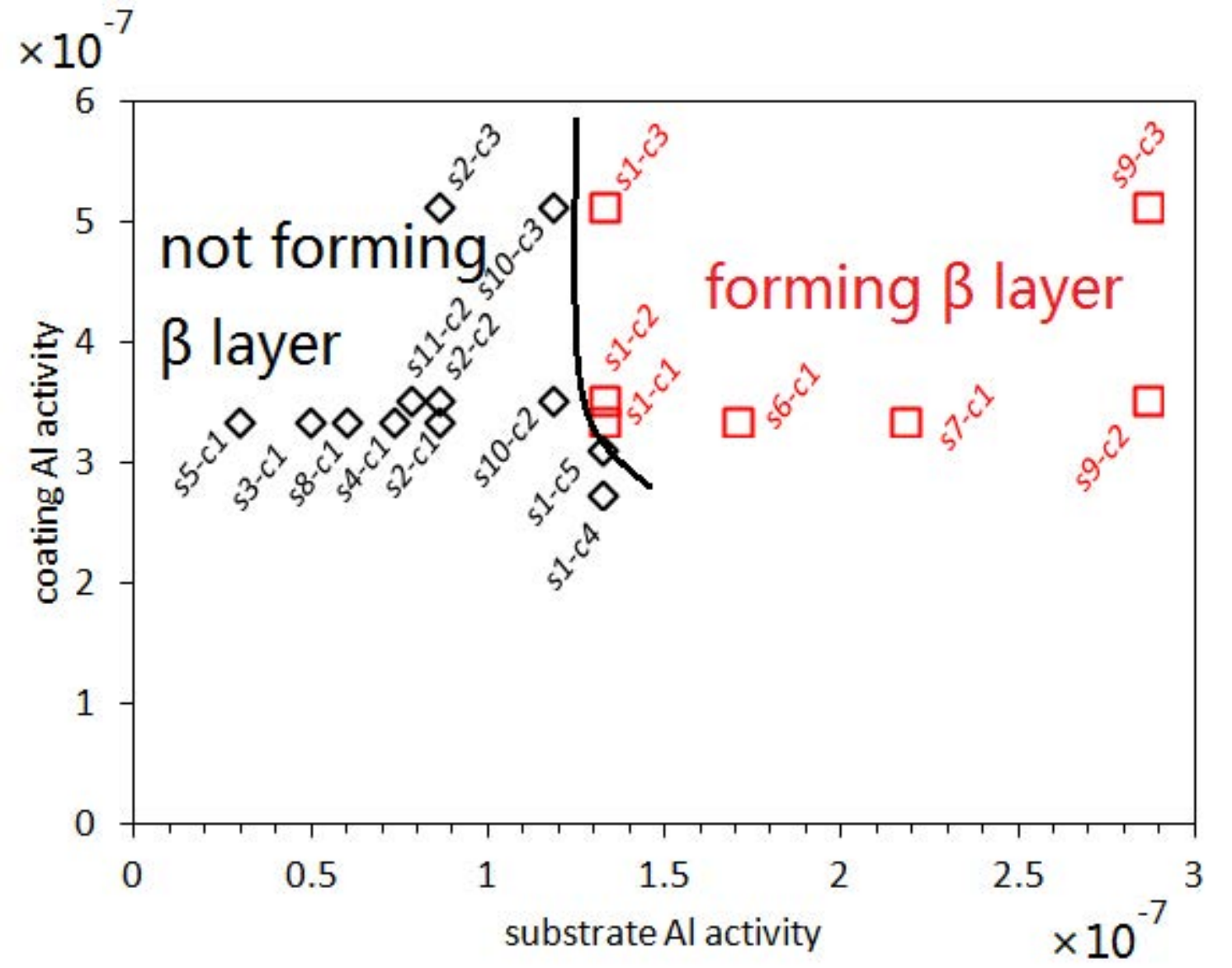

